\title{
Evaluation of gibberllins effects in association with fungicides for control grey mould in grapes merlot
}

\author{
Deise Munaro ${ }^{1}$ and Murilo César do Santos ${ }^{2}$
${ }^{1}$ Ingeniera agrónoma, Laboratorio de Fitopatología, Universidade de Caxias do Sul, Calle Francisco Getúlio Vargas, 1130 , CEP 95070-560, RS, Brazil
${ }^{2} \operatorname{Prof}^{\circ} . \operatorname{Dr}^{\circ}$ en Fitopatogía, Laboratorio de Fitopatología, Universidade de Caxias do Sul, Calle Francisco Getúlio Vargas, 1130, CEP 95070-560, RS, Brazil

\begin{abstract}
This study was conducted in a commercial vineyard, testing the effect of giberilinas biofungicides associated with the objective to control Botrytis cinerea on grape cultivar Merlot grapes. The experiment was conducted with a randomized block design with 4 treatments and 4 replications. Each plot consisted of four plants. The treatments were: 1. Pro-gibb $200 \mathrm{mg} / \mathrm{L}$ pre-flowering, repeated after 10 days at a dose $200 \mathrm{mg} / \mathrm{L} 2$. Pro-gibb in pre-flowering, repeated after 10 days, the dose of $300 \mathrm{mg} / \mathrm{L} ; 3$. Pro-gibb $200 \mathrm{mg} / \mathrm{L}+$ Serenade 4 $\mathrm{mL} / \mathrm{L}$ in pre-flowering, in pre-bloom and full bloom, both pellet repeated in stadiums and early grain maturity 4. Pro-gibb $300 \mathrm{mg} / \mathrm{L}$ and Stimulate $4 \mathrm{~mL} / \mathrm{L}$ in pre-flowering, in full bloom, repeated grain pellet and early maturation. The treatment Pro-Gibb $300 \mathrm{mg} / \mathrm{L}+$ Serenade $4 \mathrm{~mL} / \mathrm{L}$ showed a control of $67 \%$ compared to gray mold. The treatments did not show satisfactory results for average weight of bunches and ${ }^{\circ}$ Brix. All treatments showed a higher growth of the rachis compared to control and to control Botrytis cinerea in the grape.
\end{abstract}

\section{Introducción}

La uva merlot és origínaria de Médoc, Francia, donde ya se cultivaba desde 1850, después se ha expandido para otros países vitícolas. Merlot ha sido introducida en el estado de Rio Grande del Sur por intermedio de la Estación Agronómica de Porto Alegre, posteriormente en 1970 fue difundida en la Serra Gaúcha, al paso que se ha tornado una de las principales viníferas tintas del estado [1]. Además, la cultivar se ha adaptado a las condiciones climáticas del sur de Brazil y presenta un potencial para vinos de alta calidad, pero és muy sensible a enfermedades provocadas por hongos como el mildiu y el podredumbre-gris [2].

Uno de los aspectos importantes para la definición de calidad en vinos, está relacionado a la sanidad de las uvas. Enfermedades afectan desde la coloración, compuestos aromáticos y el sabor [3]. La podredumbre gris, o "Botritis", causada por el hongo Botrytis cinerea, es uno de los problemas sanitarios que causa mayores pérdidas por deterioro de la uva de mesa y de variedades viníferas. La pudrición por este hongo es causante de desnaturalización de color y la aparición de un sabor desagradable en el vino, reduciendo así su calidad [4]. El desarrollo de "Botritis" depende de interacciones entre factores ambientales y bióticos, que comprende el desarrollo estacional de la vid, liberación y dispersión del inoculo, así como fenómenos de penetración del hongo e infección. La enfermedad se ha controlado por años con fungicidas aplicados en primavera y verano, donde se encuentran las condiciones más favorables al desarrollo del hongo. Sin embargo, con el paso del tiempo, el control de este hongo ha resultado más problemático, destacándose el desarrollo de resistencia por parte del hongo a los fungicidas tradicionales [5]. Por consecuencia de lo anteriormente señalado, resulta de interés evaluar nuevas alternativas de control, como es el uso de biocontroladores, de gran interés hoy en día.

En patología vegetal el control biológico se entiende como la destrucción o inhibición total o parcial de poblaciones del patógeno por otros microorganismos. En los últimos años, la utilización de estos microorganismos antagonistas, ha demostrado ser una alternativa factible al control tradicional de patógenos con productos químicos. El uso de estos antagonistas se basa en su promoción (que ocurre naturalmente) y en la introducción artificial de ellos, siendo este último el más utilizado en el control biológico [6]. Para que un antagonista se convierta en un eficaz agente de control biológico, debe ser capaz de producir inóculo abundante en cualquier condición climática, además, debe ser genéticamente estable y poseer una alta especificidad sobre el hospedero al que se quiere controlar, debe infectar y destruir eficazmente al patógeno en un amplio rango de condiciones ambientales y ser inocuo para el medio ambiente y animales [7].

Algunas bacterias, como Bacillus subtilis, Streptomyces spp. y Pseudomonas sp., también son utilizadas como organismos antagonistas. Gonzáles y Fragoso [8], señalan que Bacillus subtilis no es potencialmente patógena, no produce endotoxinas y secreta proteínas al medio, algunas de ellas con propiedades antifúngicas, como la subtilina y otros antibióticos de la familia de las iturinas. Se utiliza industrialmente como inseticida y fungicida. La subtilina liberada por $B$. subtilis actúa sobre la pared celular de hongos. El antagonismo que B.subtilis logra sob los hongos patógenos vegetales es a través de diversos mecanismos que incluyen la competencia por nutrientes; exclusión de sítio; colonización de la bacteria en el patógeno y/o la liberación de componentes celulares 
durante el crecimiento, en orden de eliminar o reducir los competidores en su medio ambiente inmediato [9].

Los reguladores de crecimiento (plant growth regulators, PGRs) han sido mayormente utilizados en agricultura, como fruticultura y viticultura, aunque existen también notables ejemplos de uso en cultivos extensivos como cereales. Las favorables características de baja toxicidade de los reguladores de crecimiento los hacen ser candidatos apropriados para incorporación en sistemas de manejo con reducido impacto ambiental. Los PGRs, en general actúan modificando el crecimiento y desarrollo de las plantas a través de su acción sobre vías y pasos bioquímicos específicos, normalmente relacionados con regulación por hormonas vegetales [10].

Las giberilinas son hormonas de crecimiento diterpenoides tetracíclicos involucrados en varios procesos de desarrollo en vegetales. A pesar de ser más de 100 el número hallado en plantas, sólo son unas pocas las que demuestran actividad biológica. El efecto más notable de las Giberilinas es inducir crecimiento en altura y el desarrollo súbito de inflorescencias y la floración en muchas plantas. Promueven también el desarrollo de muchos frutos, inducen partenocarpia y tienen una aplicación especial en la producción de uvas "sin semillas" [11].

Otra clase de hormonas, las citocininas, son esenciales en el accionar de varios vinculados al crecimiento y desarrollo de las plantas y relacionados a la acción de varios genes. Gran parte de las respuestas de totipotencia celular, de morfogénesis in vitro y de regeneración de plantas, ocurre en presencia de niveles apropriados de citocininas vs. auxina [12].

El uso de giberilinas en viticultura para aumentar el tamaño de bayas en uvas de cultivar Itália, estudiada por Zonetti \& Rolla [13], aplicándose $0,051 \mathrm{~g} / \mathrm{L}$ diecisiete días después de la floración, presentando diferencias en relación al testigo en aumento de peso y aumento de tamaño de bayas, pero no mayor en ${ }^{\circ}$ Brix. En otro experimento de lo mismo autor, testándose la cultivar Vênus, con la aplicación $30 \mathrm{mg} / \mathrm{L}$ de ácido gíberelico, catorze días después de la floración, sumergiéndose los racimos, presentando un aumento del ancho de la raquis y el numero de bayas.

Con el propósito de mejorar la calidad de los productos finales de la uva, como el vino, propone se en este trabajo utilizar reguladores de crecimiento juntamente con biofungicidas, donde esperase que el mayor crecimiento de la raquis proporcione una distancias y aeración entre las bayas, o sea, una menor compacidad evitando así el desarrollo del hongo patógeno. Además de eso, é utilizase, de productos que sean de menor toxicidad al ambiente.

\section{Metodología}

El ensayo fue conducido en viñedos localizados en el interior de la ciudad de Nova Pádua, RS, en la Serra Gaúcha, en las coordenadas geográficas latitud $29^{\circ} 00^{\prime} 50,13^{\prime \prime} \mathrm{S}$ y longitud $51^{\circ} 18^{\prime} 29,94^{\prime \prime} \mathrm{W}, 683 \mathrm{~m}$ de altitud. Fueran utilizadas viñas de la cultivar merlot, injertadas sobre porta injerto Paulsen 1103, en parronal de ocho años, el espaciamiento entre plantas y líneas de 2,2 m. El ensayo fue realizado con delineamiento en bloques casualizados con cuatro tratamientos y cuatro repeticiones. Cada una de las parcelas fue constituida por cuatro plantas,
Tabla 1. Tratamientos y dosis aplicadas.

\begin{tabular}{|c|c|c|}
\hline Tratamientos & $\begin{array}{c}\text { Período de } \\
\text { aplicación }\end{array}$ & $\begin{array}{c}\text { Producto y dosis } \\
\text { mg/L o mI/L }\end{array}$ \\
\hline Giberilina & PF* DPF* $^{*}$ & Pro-Gibb 200,0 \\
\hline Giberililina & PF* DPF* $^{*}$ & Pro-Gibb 300,0 \\
\hline $\begin{array}{c}\text { Giberilina }+ \\
\text { Biofungicida }\end{array}$ & PLF* BAY* IM* $^{*}$ & Pro-Gibb 200,0+4,0 \\
\hline $\begin{array}{c}\text { Giberilina }+ \\
\text { Biofungicida }\end{array}$ & PLF* BAY* IM* $^{*}$ & Pro-Gibb 300,0+4,0 \\
\hline
\end{tabular}

PF*; pré floración, DPF*; después diez días de la prefloración, $\mathrm{PLF}^{*}$; plena floración, $\mathrm{BAY} *$; bayas de 2-3 mm de diámetro, $\mathrm{IM}^{*}$; inicio de maduración.

donde las dos plantas centrales como área útil y las demás como bordura. Los siguientes tratamientos (Tabla 1) fueran aplicados en aspersiones dirigidas al racimo, en diferentes estados fenológicos de la planta.

Evaluaciones de cinco racimos de las plantas consideradas como área útil fueran colectadas, pesados y evaluados el porcentaje de incidencia y severidad del patógeno e el ${ }^{\circ}$ Brix. De dos racimos de cada planta central midieron se periódicamente el largo y ancho con un vernier graduado en mm para la determinación del tamaño medio de longitud.

Las determinaciones de porcentaje e incidencia se ha realizado por la determinación de presencia o ausencia de bayas contaminadas por Botrytis cienerea. Se ha utilizado también una evaluación de porcentaje del control por la siguiente ecuación [14]:

$$
\% \text { Control }=\frac{(\mathrm{T}-\mathrm{t}) 100}{\mathrm{t}}
$$

Donde;

$\mathrm{T}=\%$ incidencia del testigo

$\mathrm{t}=\%$ incidencia en el tratamiento.

Las análisis para la determinación de ${ }^{\circ}$ Brix fueran realizadas con una balanza para medir densidad, con correcciones a $20^{\circ} \mathrm{C}$.

\section{Resultados}

Los datos obtenidos en el ensayo están dispuestos y presentados en las Tablas 2 y 3 .

La Tabla 2 que presenta la evaluación de la incidencia de racimos con pudrición gris en plantas de vid cv. Merlot en la cosecha, se registró $2,7 \%$ de racimos con pudrición gris en el tratamiento (4) Pro-gibb + Serenade, por lo tanto presentando una incidencia significativamente menor a la manifestada por el tratamiento testigo, lo que se confirma en la porcentaje de control de $67 \%$. Los demás tratamientos no difirieron en relación al testigo (5). Del mismo modo, los tratamientos testados para evaluar el porcentaje de severidad en los racimos (Tabla 2), mostró que no difieren estadísticamente en relación al testigo.

En la Tabla 3 presentase el resultado de los tratamientos en relación al tamaño longitudinal de los racimos. Lo que se observó, que todos los tratamientos excepto el tratamiento 3 (Pro-gibb + Serenade en dosis más baja de giberilina) han presentado un crecimiento mayor en relación al testigo. Los tratamientos no difirieron entre el valor medio de los sólidos solubles totales, presentándose en $19,6^{\circ}$ BRIX. 
Tabla 2. Evaluación de los tratamientos en relación a incidencia y severidad de Botrytis cinerea. en uvas cv. Merlot.Nova Pádua, RS.

\begin{tabular}{lcccc}
\hline \hline Tratamientos & $\begin{array}{c}\text { Dosis (mg /L) } \\
+(\mathrm{ml} / \mathrm{L})\end{array}$ & $\begin{array}{c}\text { Incidencia } \\
(\%)\end{array}$ & Severidad & $\begin{array}{c}\text { Control } \\
(\%)\end{array}$ \\
\hline 1. Pro-Gibb & 200 & $6,51 \mathrm{a}$ & $2,79 \mathrm{a}$ & 0 \\
2. Pro-Gibb & 300 & $4,28 \mathrm{ab}$ & $1,89 \mathrm{a}$ & 44 \\
3. Pro-Gibb & $200+4$ & $6,52 \mathrm{a}$ & $2,39 \mathrm{a}$ & 0 \\
+ Serenade & & & & \\
4. Pro-Gibb & $300+4$ & $2,70 \mathrm{~b}$ & $2,08 \mathrm{a}$ & 67 \\
+ Serenade & & & & \\
5. Testigo & - & $6,68 \mathrm{a}$ & $2,41 \mathrm{a}$ & - \\
\hline C.V $(\%)$ & & 40,29 & 42,62 & - \\
\hline \hline
\end{tabular}

Datos transformados en $\sqrt{x+0,5}$. Medias con la misma letra, en columnas no difieren por el teste de Duncan a $5 \%$ de probabilidad.

Tabla 3. Evaluación de los tratamientos en relación a la longitud del racimo en cuatro eventos. Nova Pádua, RS.

\begin{tabular}{lccccc}
\hline \hline \multirow{2}{*}{ Tratamientos } & \multirow{2}{*}{ Dosis } & \multicolumn{4}{c}{ Longitud del Racimo (Fecha) } \\
\cline { 3 - 6 } & & $15 / 12$ & $30 / 12$ & $15 / 01$ & $30 / 01$ \\
\hline 1. Pro-Gibb & 200 & $5,11 \mathrm{a}$ & $5,02 \mathrm{bc}$ & $5,08 \mathrm{a}$ & $5,11 \mathrm{a}$ \\
2. Pro-Gibb & 300 & $5,21 \mathrm{a}$ & $5,13 \mathrm{ab}$ & $5,15 \mathrm{a}$ & $5,16 \mathrm{a}$ \\
3. Pro-Gibb & $200+4$ & $5,25 \mathrm{a}$ & $5,04 \mathrm{abc}$ & $5,05 \mathrm{ab}$ & $5,06 \mathrm{ab}$ \\
+ Serenade & & & & & \\
4. Pro-Gibb & $300+4$ & $5,16 \mathrm{a}$ & $5,28 \mathrm{a}$ & $5,27 \mathrm{a}$ & $5,24 \mathrm{a}$ \\
+ Serenade & & & & & \\
5. Testigo & - & $4,84 \mathrm{a}$ & $4,85 \mathrm{c}$ & $4,87 \mathrm{~b}$ & $4,87 \mathrm{~b}$ \\
\hline C.V $(\%)$ & & 2,70 & 3,07 & 2,62 & 2,55 \\
\hline \hline
\end{tabular}

Datos transformados en $\sqrt{x+0,5}$. Medias con la misma letra, en columnas no difieren por el teste de Duncan a $5 \%$ de probabilidad. ${ }^{1}$ Dosis $(\mathrm{mg} / \mathrm{L}$ o $\mathrm{mL} / \mathrm{L})$.

\section{Discusión y conclusiones}

Durante la temporada vitivinícola 2011-2013 fue posible constatar la eficacia del biocontrolador del producto

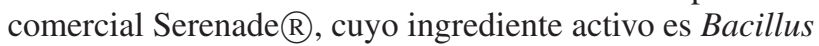
subtilis para el control pudrición gris en un parronal de vid cv. Merlot. El método más tradicional de conducir viñas en el sur de Brasil, indiscutiblemente permite satisfacer más fácilmente las condiciones de humedad y temperatura que Botrytis cinerea requiere para la infestación. $B$. subtilis ha demostrado inducir una resistencia sistémica adquirida natural de la planta contra patógenos bacterianos y fungosos [9]. En este estudio, las aplicaciones del producto Serenade $\AA$ juntamente con el producto ProGibbß en su mayor dosis aplicadas en plena floración, bayas en tamaño guisante $(2-3 \mathrm{~mm}$ de diámetro) y en inicio de maturación, logró una eficiente reducción de la incidencia de la pudrición causada por B.cinerea en racimos de la cultivar Merlot. Sería interesante realizar nuevos ensayos para evaluar aplicaciones dirigidas durante todo el período de floración, a fin de determinar su efecto sobre las infecciones latentes que se produce en esa época.

Según los resultados obtenidos en este estudio, se sugiere que una dosis intermedia entre el tratamiento 4 optimice tanto el crecimiento de la raquis así como interfiera en un control de $B$. cinerea, de esta maniera habiendo así otra alternativa para la disminución de la incidencia del patógeno.

\section{Referencias}

[1] J. Tonietto, Vinhos brasileiros de $4^{a}$ geração (Comunicado técnico), Bento Gonçalves (2003)

[2] J. Meneguzzo. L.A. Rizzon. A.Mielle. M.A.Z. Ayub. Efeito de Botrytis cinerea na composição do vinho Gewürztraminer. Ciência e Tecnologia de alimentos, Campinas (2006)

[3] A.L. Rizzon, A. Mielle. F. Mandelli. Manejo do dosel vegetativo da videira e seu efeito na composição do vinho Merlot. Pesquisa agropecuária brasileira. 44. n5, p463-470 (2009)

[4] J. Auger. La pudrición gris de la vid. Revista Frutícola.7 (1981)

[5] B. Latorre. Manejo de Botrytis cinereaen Uva de mesa. Revista Frutícola. 7(1986)

[6] L. Ciampi, S. Silva. Perspectivas para el Control Biológico de Botrytis cinereaen frambueso. Revista Aconex. (1991)

[7] A. Morales. Botrytis en vides Chile hortofrutícola. 45. (1997)

[8] V. Gonzáles. S. Fragoso. Bacillus subtilis. Disponible http://www2.cbm. uam.es/microali/pdfs/ Bsubtilis.pdf . Consultado: octobre (2010)

[9] M.T. Butt. J.G. Harris K..A. Powell. Microbial Biopesticides. The european scene (1999)

[10] J. Retamales. Actualización en hormonas vegetales y reguladores de crecimiento:aspectos básicos y modos de acción. Valent Bio Sciences Corporation. Universidad de Chile (2005)

[11] K. Kato. H. Ohara. E. Takahashi. Endogenous gibberellin-induced parthenocarpy in grape berries. Acta Horticulturae. 514 (2000)

[12] C. Coenen \& L.T. Lomax. Auxin-cytokinin interactions in higher plants: old problems and new root.Trends Plant Science 2.351-356 (1997)

[13] M. A. Tecchio. R. Botelho. V. Pires. M.M. Terra. J.L. Hernandes. Efeitos do CCPU e do ácido giberélico nas características morfológicas dos cachos $e$ bagas da uva 'vênus'. Acta Scietiarum Agronomy, Maringá. 28. 507-511 (2006)

[14] W.S. Abbott. A method for computing effetiveness of on inseticide. Journal of Economic Entomology. Maryland. 13, n1 265-267 (1925) 